American Journal of Applied Sciences 8 (1): 45-49, 2011

ISSN 1546-9239

(C) 2010 Science Publications

\title{
Effect of Temperature on the Color of Natural Dyes Extracted Using Pressurized Hot Water Extraction Method
}

\author{
Nursyamirah Abd Razak, Siti Marsinah Tumin and Ruziyati Tajuddin \\ Department of Chemistry, Faculty of Applied Science, University Technology MARA, \\ 40450 Shah Alam, Selangor, Malaysia
}

\begin{abstract}
Problem statement: Traditionally, extraction of natural dyes with boiling method produced only one single tone of colorant/dyes which involved plenty of water in several hours of extraction time. A new modern extraction technique should be introduced especially to textile dyers so that a variety of tone of colorants can be produced in a shorter time with less consumption of water. Approach: This study demonstrated Pressurized Hot Water Extraction (PHWE) as a new technique to extract colorants from a selected plant, i.e., Xylocarpus moluccensis species which can be found abundantly in Peninsular Malaysia. Colorant from the heartwood of Xylocarpus moluccensis was extracted at different elevated temperatures, from $50^{\circ} \mathrm{C}$ up to $150^{\circ} \mathrm{C}$ using PHWE technique and the extracts obtained were compared to those obtained via boiling method at $100^{\circ} \mathrm{C}$. The color strength of dye extracts was then analyzed using UV-Visible spectrophotometer and Video Spectral Comparator (VSC 5000). The effect of the extraction temperatures on the color of extracts obtained by PHWE was also investigated. Results: Results show that the colorimetric data obtained from VSC reading exhibited the exact tone of colors found in anthraquinone. UV-Visible spectrum also shows that higher absorbance of natural dyes extracted via PHWE compared to those obtained by boiling method. Conclusion: By using PHWE employed at different elevated temperatures, different tones of colorants can be produced from one single source in a shorter time with less consumption of water.
\end{abstract}

Key words: UV-visible spectrophotometer, video spectral comparator, natural colorant, anthraquinone, Pressurized Hot Water Extraction (PHWE), extraction temperature, Xylocarpus moluccensis, deionized water

\section{INTRODUCTION}

Xylocarpus moluccensis, also known as Possur, is one of the Meliaceae families which can be found abundantly in Peninsular Malaysia (Sarker et al., 2007). The wood of this plant consists of two parts which are sapwood (yellow) and heartwood (dark red). Preliminary study in our laboratory showed that the heartwood is rich with dye yielding properties. Today, the use of natural dyes in textile dyeing has once again gained interest as an important alternative to synthetic dyes which have been reported to have carcinogenic effects and have caused pollution to the natural environment (Meena et al., 2009 and Ong et al., 2010). Moreover it is critical to explore natural dyes sources from abundantly occurring plant.

Traditionally most rural textile dyers employed boiling method with water to extract natural dyes from plant species. Unfortunately, this method consumed plenty of water in order to produce a single tone of dye extract in several hours of extraction time. It is therefore important that the most efficient extraction method be utilized in textile dyeing. Although many workers have reported on application of pressurized hot water for extraction of organic compounds from plant species, none of them exploited the method to produce natural dyes for textile dyeing. The term "pressurized hot water" refers to water at high temperatures up to its critical temperature $(547.3 \mathrm{~K})$ and at the pressure high enough to maintain it in the liquid state. At higher temperature than ambient, water dielectric constant decreases and thereby decreasing its polarity. As a result, the solubility of organic compounds in water increases (Pongnaravane et al., 2006). Increasing the water temperature from $25-250^{\circ} \mathrm{C}$ causes similar changes in solvent polarity, surface tension and viscosity as those achieved by conventional mixing of methanol or acetonitrile with water (Yang et al., 1998). Anthraquinones from the roots of Morinda citrifolia were extracted by Shotipruk et al. (2004) using Pressurized

Corresponding Author: Ruziyati Tajuddin, Faculty of Applied Sciences, University Technology MARA, 40450 Shah Alam, Selangor, Malaysia Tel: 603-55444453 Fax: 603-55444562 
Hot Water Extraction (PHWE) method at different temperatures of 110,170 and $220^{\circ} \mathrm{C}$. Their study showed that the extraction yield increases as the temperature increased resulting of the increased solubility; however the pressure did not affect the extraction yield.

The aim of this study was to develop a simple method to extract natural dyes using Pressurized Hot Water Extraction (PHWE) employed at different elevated temperatures. The effect of different extraction temperatures range from $50-150^{\circ} \mathrm{C}$ on the color of the natural dyes was also investigated.

\section{MATERIALS AND METHODS}

Raw materials: The wood of Xylocarpus moluccensis was collected from Carey Island, Klang, Malaysia. The sample was then ground and stored at room temperature before use.

Chemicals: Standard anthraquinone (purpurin) was purchased from Fluka, Swirtzerland. Pure water was obtained from Millipore Alpha-Q water system. Deionized/distilled water was used as a solvent for extraction and $99.996 \%$ nitrogen gas was applied to keep the pressure high during extraction with PHWE method.

Sample preparation: Extraction was performed using PHWE system (Model ASE200, Dionex Corporation). Approximately $2 \mathrm{~g}$ of dried ground sample was weighed and transferred into $22 \mathrm{~mL}$ extraction cell with a cellulose filter placed at the bottom of each cell. The effect of PHWE temperature on the yield of colorant was examined at temperatures of 50,75, 100, 125 and $150^{\circ} \mathrm{C}$ with the extraction pressure of 1000 psi using deionized water as the solvent. The static time for the extraction to be completed was $10 \mathrm{~min}$ with two cycles of extract.

Boiling method: Approximately $2 \mathrm{~g}$ of dried ground sample was weighed and transferred into $100 \mathrm{~mL}$ conical flask. About $40 \mathrm{~mL}$ of distilled water was added to the conical flask based on mass to liquid ratio (M: L) 1:20. The sample was boiled using hot plate to $100^{\circ} \mathrm{C}$ for $30 \mathrm{~min}$ at atmospheric pressure.

All extracts were filtered and dried using rotary evaporator at $50^{\circ} \mathrm{C}$ and redissolved in distilled water for UV-Visible spectroscopic analysis and color measurement using Video Spectral Comparator.

Chemical analysis: UV-Vis spectrometry: The absorbance of the extracted sample was measured using Perkin Elmer Lambda 35 spectrophotometer at wavelength range from 200-600 $\mathrm{nm}$. The detector used was diode array detector with deionized water as the solvent.

Color measurement: Color of extracts were measured using Video Spectral Comparator (VSC 5000, Foster and Freeman, UK) based on CIE system (International Commission on Illumination, Vienna) expressed as $\mathrm{L}^{*}$, $a^{*}$ and $b^{*}$ which representing lightness $\left(\mathrm{L}^{*}\right)$, redness $\left(+a^{*}\right)$, greenness $\left(-a^{*}\right)$, yellowness $\left(+b^{*}\right)$ and blueness $\left(-b^{*}\right)$ (Wrolstad et al., 2005). From the $\mathrm{L}^{*}, \mathrm{a}^{*}$ and $\mathrm{b}^{*}$ coordinates, chroma $\left(\mathrm{C}^{*}\right)$ and hue angle $\left(\mathrm{h}^{\circ}\right)$ values were calculated using the following equation:

$\mathrm{C}^{*}=\left(\mathrm{a}^{* 2}+\mathrm{b}^{* 2}\right)^{1 / 2}$ and $\mathrm{h}^{\circ}=\tan ^{-1}\left(\mathrm{~b}^{*} / \mathrm{a}^{*}\right)$

Chroma $\left(\mathrm{C}^{*}\right)$ is a measure of intensity or saturation while, hue angle $\left(\mathrm{h}^{*}\right)$ is expressed on $360^{\circ}$ grid to show the tonality of color. Red colors are represented by $\mathrm{h}^{\circ}$ values around $0^{\circ}$ (or $360^{\circ}$ ), blue colors are described by values close to $270^{\circ}$ (or $-90^{\circ}$ ). Yellow colors are illustrated with hue angle near $90^{\circ}$ and green colors are found close to $180^{\circ}$ (or $-80^{\circ}$ ) (Torskangerpoll and Anderson, 2005).

\section{RESULTS}

Analysis using UV-Visible spectrophotometer: The maximum absorbance of each crude dyes extracted at different temperature was measured by UV-Visible spectrophotometer in a wavelength range of 250-600 $\mathrm{nm}$ as shown in Fig. 1. The $\lambda_{\max }$ of each extract observed in the curve recorded perfectly matched to that of standard purpurin (Rashwan et al., 2005), one of the major anthraquinone compounds which was anticipated present in the crude extract.

The visible spectrum of colorant extracted by PHWE at $100^{\circ} \mathrm{C}$ was then compared to that obtained by boiling method at $100^{\circ} \mathrm{C}$ with atmospheric pressure. Fig. 3 shows that the maximum absorbance obtained at $\lambda_{\max } 477 \mathrm{~nm}$ for PHWE extract was higher than the latter extract.

Color measurement of crude dye extracts: The analytical assessment of aqueous plant extract is important in order to control the quality and standardization of the natural colorant before proceeds for further application such as textile dyeing. 
Am. J. Applied Sci., 8 (1): 45-49, 2011

Table 1: Chromaticity values for standard purpurin and crude dyes of Xylocarpus moluccensis heartwood extracted at temperature of 50, 75, 100, 125 and $150^{\circ} \mathrm{C}$

\begin{tabular}{lcrrrr}
\hline Extraction temperature $\left({ }^{\circ} \mathrm{C}\right)$ & \multicolumn{1}{c}{$\mathrm{L}^{*}$} & \multicolumn{1}{c}{$\mathrm{a}^{*}$} & \multicolumn{1}{c}{$\mathrm{b}^{*}$} & \multicolumn{1}{c}{$\mathrm{h}^{\circ}$} & $\mathrm{C}^{*}$ \\
\hline 50 & $32.3 \pm 1.110$ & $17.4 \pm 0.25$ & $(-) 2.6 \pm 1.46$ & $(-) 8.5 \pm 4.530$ & $17.6 \pm 0.480$ \\
75 & $29.5 \pm 0.300$ & $26.2 \pm 0.49$ & $0.8 \pm 0.40$ & $26.2 \pm 0.840$ & $26.3 \pm 0.500$ \\
100 & $29.7 \pm 1.330$ & $27.7 \pm 0.75$ & $10.9 \pm 0.79$ & $21.5 \pm 0.930$ & $29.7 \pm 0.980$ \\
125 & $37.57 \pm 0.68$ & $26.5 \pm 0.36$ & $15.4 \pm 0.46$ & $30.65 \pm 1.04$ & $30.65 \pm 0.19$ \\
150 & $51.9 \pm 1.390$ & $23.3 \pm 0.50$ & $24.9 \pm 1.50$ & $46.8 \pm 1.180$ & $34.1 \pm 1.420$ \\
Standard purpurin at room temperature & $61.8 \pm 0.900$ & $19.4 \pm 0.50$ & $17.0 \pm 0.67$ & $41.2 \pm 1.090$ & $25.6 \pm 0.180$ \\
\hline
\end{tabular}

$\mathrm{L}^{*}=$ lightness, $\mathrm{a}^{*}=$ redness, $-\mathrm{a}^{*}=$ greenness, $\mathrm{b}^{*}=$ yellowness, $-\mathrm{b}^{*}=$ blueness, $\mathrm{h}^{*}=$ hue angle and $\mathrm{C}^{*}=$ chroma

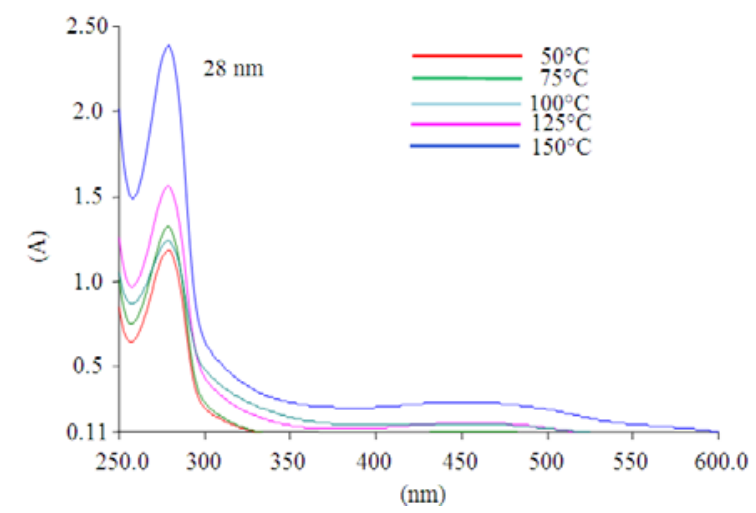

Fig. 1: Spectrum of natural colorant extracted at 50, 75, 100,125 and $150^{\circ} \mathrm{C}$

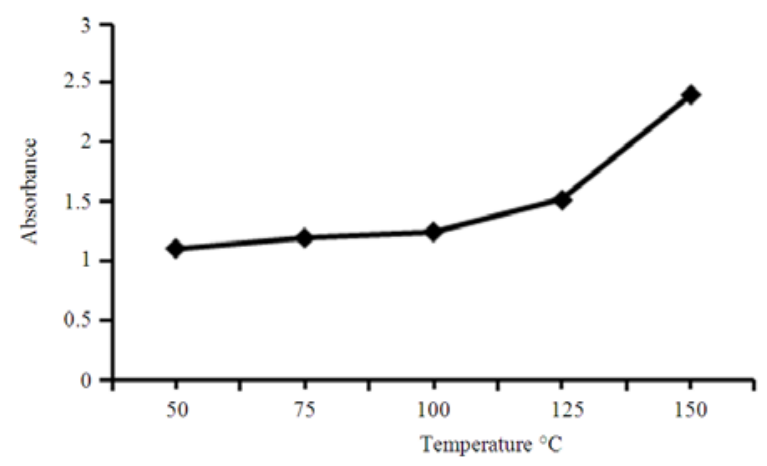

Fig. 2: Graph of absorbance against extraction temperature at $\lambda_{\max } 280 \mathrm{~nm}$

The color measurement revealed that enhanced color intensity related to characterization of increased absorptivity color effects which also covers variations of lightness and saturation (Gonnet, 1999). In this study, the measurement of $\mathrm{L}^{*}, \mathrm{a}^{*}$ and $\mathrm{b}^{*}$ as well as $\mathrm{h}^{\circ}$ and chroma $\mathrm{C}^{*}$ values was used to evaluate the color of crude dyes of Xylocarpus moluccensis heartwood extracted at different elevated temperatures.

Table 1 shows the value of $L^{*}, a^{*}$ and $b^{*}$ obtained from measurement using VSC based on CIE system. By applying the CIE system, hue angle $\mathrm{h}^{\circ}$ and chroma $\mathrm{C}^{*}$ value were calculated using the formula mentioned earlier.

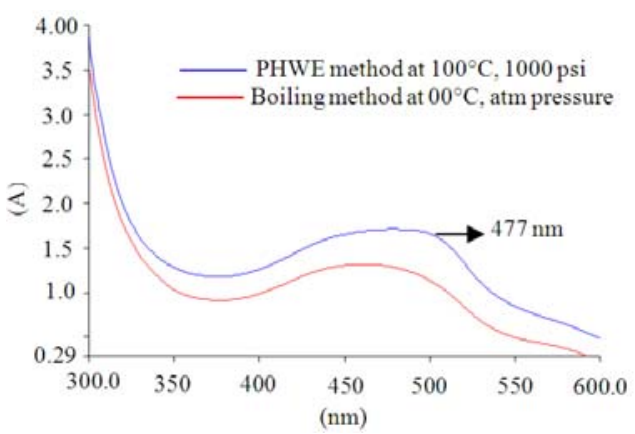

Fig. 3: Spectrum of natural colorant extracted by PHWE and boiling methods at $100^{\circ} \mathrm{C}$

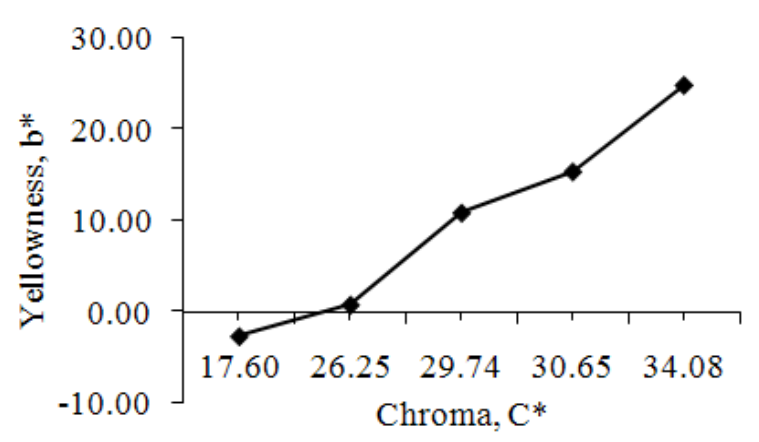

Fig. 4:Graph $b^{*}$ value against $C^{*}$ value at 5 different temperatures

Based on the calculated $h^{\circ}$ value, the color of the crude dyes extracted at $50^{\circ} \mathrm{C}$ was bluish purple. As the extraction temperature was raised up to $100^{\circ} \mathrm{C}$, tonality of color changed from bluish purple to red purple. This was indicated by the changes of $b$ * value from (-) 2.610.9 which means the blueness effect become weaker whilst the yellowness effect become stronger. At this condition, the value of $(+) \mathrm{a}^{*}$ that indicates the redness effect was increased from 17.4-27.7 However as the temperature increasing up to $150^{\circ} \mathrm{C}$, the redness effect slightly decreasing while the yellowness effect becoming more dominant which gave yellowish-orange tone for the crude dyes extract and this correlate to the color of standard purpurin. The $\mathrm{h}^{\circ}$ value of crude dyes extract at $150^{\circ} \mathrm{C}$ was 46.8 which was comparable to the $\mathrm{h}^{\circ}$ value of standard purpurin. 
The intensity or saturation of colorant is represented by chroma, $\mathrm{C}^{*}$ value. The positive correlations between $b^{*}$ and $C^{*}$ is shown in Fig. 4. Results in Table 1 shows that the chroma, $\mathrm{C}^{*}$ value of the crude dyes extracted at $150^{\circ} \mathrm{C}$ was highest which is near to 50 that represents the occurrence of bright colors (Almela et al., 1995). Thus, it was discovered that natural dyes extracted at $150^{\circ} \mathrm{C}$ has the highest intensity and brightest of color compared to the other extracts at lower temperatures.

\section{DISCUSSION}

Temperature is the main factor which affects the extraction efficiency and selectivity in PHWE. It could influence the physicochemical properties of water whereby at high temperature, polarity of water decreasing and thus enhancing the solubility of less polar compounds in water. Results in this study (Fig. 1 and 2) show that as the temperature increasing gradually from $50^{\circ} \mathrm{C}$ up to $150^{\circ} \mathrm{C}$, the maximum absorbance of Xylocarpus moluccensis extracts at $\lambda_{\max } 280 \mathrm{~nm}$ and 477 $\mathrm{nm}$ increasing which correspond to that of standard purpurin (anthraquinone compound). This explains that at higher temperature, water was able to extract larger amount of less polar compound such as purpurin.

Visible spectrum in Fig. 3 shows that by utilizing PHWE method at $100^{\circ} \mathrm{C}$ and 1000 psi, higher yield of natural dyes was obtained compared to that of boiling method at atmospheric pressure even though longer extraction time was employed in the latter method.

CIELAB parameters help to give an exact tone of color of the natural dyes. Differences in tonality of color among the natural dyes extracted from the wood of Xylocarpus moluccensis at $50^{\circ} \mathrm{C}$ up to $150^{\circ} \mathrm{C}$ were observed based on $\mathrm{L}^{*}, \mathrm{a}^{*}$ and $\mathrm{b}^{*}$ measurement ranging from bluish purple to orange-yellowish. The positive correlations between $\mathrm{b}^{*}$ and $\mathrm{C}^{*}$ as shown in Fig. 4 indicate that an increase in color intensity of Xylocarpus moluccensis extracts corresponds with saturated yellowish color.

\section{CONCLUSION}

By employing PHWE method at different extraction temperatures, different tones of colorants can be produced from one single source in a shorter time with less consumption of water. Chromaticity values of hue angle, $\mathrm{h}^{\circ}$ shows that tonality of color of natural dyes extracted from the wood of Xylocarpus moluccensis ranging from bluish-purple to orangeyellowish. Chroma, $C^{*}$ when relate to $b^{*}$ value proves that extraction temperatures have the significant effect on the intensity of the orange-yellowish color of the natural dyes which correspond to the color of standard anthraquinone, purpurin.

\section{ACKNOWLEDGEMENT}

We wish to express our gratitude to the Research Management Institute (RMI) of UiTM Malaysia, for financial support.

\section{REFERENCES}

Almela, L., S. Javaloy, J.A. Fernendez-Lopez and J.M. Lopez-Roca, 1995. Comparison between the tristimulus measurements Yxy and $\mathrm{L} * \mathrm{a} * \mathrm{~b} *$ to evaluate the colour of young red wines. Food Chem., 35: 321-327. DOI: 10.1016/03088146(95)93940-S

Gonnet, J.F., 1999. Colour effects of co-pigmentation of anthocyanins revisited-2. A colorimetric look at the solutions of cyanin co-pigmented byrutin using the CIELAB scale. Food Chem., 66: 387-394. DOI: 10.1016/S0308-8146(99)00088-6

Meena, R.C., R.B. Pachwarya, V.K. Meena and S. Arya, 2009. Degradation of textile dyes ponceau-S and sudan IV using recently developed photocatalyst, immobilized resin dowex-11. Am. J. Environ. Sci., 3: 444-450. DOI: 10.3844/ajessp.2009.444.450

Ong, S.T., P.S. Keng and C.K. Lee., 2010. Basic and reactive dyes sorption enhancement of rice hull through chemical modification. Am. J. Environ. Sci., 4: 447-452. DOI: 10.3844/ajassp.2010.447.452

Pongnaravane, B., M. Goto, M. Sasaki, T. Anekpankul and P. Pavasant et al., 2006. Extraction of anthraquinones from roots of Morinda citrifolia by pressurized hot water: Antioxidant activity of extracts. J. Supercritical Fluids, 37: 390-396. DOI: 10.1016/j.supflu.2005.12.013

Rashwan, F.A., H.S. Mohran and A.A. El-samahy, 2005. Electrochemical characteristics of some purpurins in aqueous and nonaqueous solutions. Am. J. Applied Sci., 7: 1174-1177. DOI: 10.3844/ajassp.2005.1174.1177

Sarker, S.D., S.J. Uddin, J.A. Shilpi, R. Rouf and M.E.M. Ferdous, 2007. Neuropharmacological properties of Xylocarpus moluccensis. J. Fitoterapia, 78: 107-111. DOI: 10.1016/j.fitote.2006.09.029 
Shotipruk, A., J. Kiatsongserm, P. Pasavant, M. Goto and M. Sasaki, 2004, Pressurized Hot Water Extraction of anthraquinones from the roots of Morinda citrifolia, Biotechnol. Prog., 20: 18721875. DOI: $10.1021 /$ bp049779x

Torskangerpoll, K. and O.M. Andersen, 2005. Colour stability of anthocyanins in aqueous solutions at various $\mathrm{pH}$ values. Food Chemistry, 89: 427-440. DOI: 10.1016/j.foodchem.2004.03.002
Wrolstad, R.E., R.W. Durst and J. Lee, 2005. Tracking colour and pigment changes in anthocyanin products. Trend Food Sci. Technol., 16: 423-428. DOI: 10.1016/j.tifs.2005.03.019

Yang, Y., M. Belghazi, A. Lagadec, D.J. Miller and S.B. Hawthorne, 1998. Elution of organic solutes from different polarity sorbents using subcritical water. J. Chromatography A, 810: 149-159. DOI: 10.1016/S0021-9673(98)00222-2 